\title{
Essential Oils from Two Species of Aromatics Plants from Mozambique, their Chemical Constituents and Bioactivity on Escherichia coli and Staphylococcus aureus
}

\author{
Alfredo Bartolomeu ${ }^{1 *}$, Silva Fabião Mujovo ${ }^{2}$ and Jóse Carlos Langa ${ }^{3}$ \\ ${ }^{1}$ Lecturer at Rovuma University Mozambique/Montepuez, Master in Natural Products, Chemistry, Mozambique \\ ${ }^{2}$ In Science Plant and Lecturer at UP/Maputo, Mozambique \\ ${ }^{3}$ Master in Epidemiology and lecturer at UEM/Maputo, Mozambique \\ *Corresponding Author: Alfredo Bartolomeu, Lecturer at Rovuma University Mozambique/Montepuez, Master in Natural Products, \\ Chemistry, Mozambique.
}

Received: July 08, 2019; Published: September 30, 2019

\begin{abstract}
In search of low cost, safe alternatives that will help in a heathy way the herbal environment for the treatment of certain diseases, the effectiveness of essential oils Cymbopogon citratus and Ocimum basilicum, are two promising species in this study. However, the study aimed to evaluate the chemical composition and antibacterial activity of the essentials oils of Cymbopogon citratus and Ocimum basilicum. Plant leaves were harvested and dried and essential oils extracted by hydrodistillation in a Clevenger apparatus. Identification of the chemical composition was performed by gas chromatography coupled to mass spectrometry (GC MS). The antibacterial activity was assessed by the disc diffusion method and minimum inhibitory concentration (MIC) at different dilutions with 99\% DMSO with distilled water against E. coli ATCC 25922 and S. aureus ATCC 25923. Ciprofloxacin was used as a positive control for bacterium at the concentration of $50 \mu \mathrm{g} / \mathrm{disc}$. The essential oil of Cymbopogon citratus and Ocimum basilicum revealed the presence of oxygenated monoterpenes, monoterpene and diterpene hydrocarbons as major compounds; of the activity to the microorganisms tested and the MIC was $50 \mathrm{mg} / \mathrm{ml}$, with a percentage of $1.65 \%$ and $1.38 \%$. The antibacterial activity was greater in relation to the halos formed. In vitro results indicate that Cymbopogon citratus may act as an antibacterial agent against infections caused by bacterium.
\end{abstract}

Keywords: Essential Oil; Chemical Composition; Antibacterial Activity; Cymbopogon citratus; Ocimum basilicum

\section{Introduction}

Mozambique is an important repository of biological diversity. This diversity is used by about $90 \%$ of the country's population mainly in rural areas to meet their housing, energy, food and health needs [1]. According to Krog., et al. [2] (Estimated at about 5,500 species of plants) are used by rural communities for medicinal purposes and play a key role in basic health care. The consumption of plants for food in Mozambique is already a practice very old and known by the first men who have passed and lived in the country. Hence, the consumption of Cymbopogon citratus (Chabakate) and Ocimum basilicum (Mbuaco) as food species and their aromatic richness were already known and used as tea and as seasonings in the daily food of these peoples. However, the study of their essential oils in Mozambique is not well known and studied by researchers. Thus, the aromatic plants of Mozambique are revealed in this and it is confirmed the expectation that Mozambique can become a great producer of aromatic oils worldwide. And a strategy is proposed to achieve this objective, a strategy will be impotent without plans of action in relation to the potential of the country's aromatic oils, if not instrumental, of the process, which will become the proposed 
strategy for reality [3]. The demand for biologically active compounds continues to be used by the pharmaceutical industry, and has greatly encouraged their use, hence essential oils have been of great importance in their use as antimicrobial agents and antioxidants in food. In view of this vast biodiversity and the need to discover new bioactive molecules, the pharmacological study of flora is of fundamental importance (Novais., et al. 2003).

In this context, the Mozambican flora is particularly rich in its size, composition in aromatic and medicinal plants, most of them spontaneous, and the possibility of extracting the essential oils or essences for the food, clothing, perfumes and basic materials industry for numerous processes chemicals. The plants are very important that in their and they become of them the source for great diversities of compounds with application in the medicine, in the pharmaceutical industry and in the food industry.

In this order, the interest in these plants is based on the aroma that these species release, hence the reason why this study is carried out to evaluate the antibacterial activity and the chemical composition of the essential oils of these species in vitro on $E$. coli and S. aureus.

\section{Materials and Methods}

The oils used in this article were obtained by the hydrodistillation process using a Clevenger type extractor. The extraction was carried out in the laboratory of the Center for Research and Development in Ethnobotany (CIDE) Namaacha. The species used to obtain the essential oils were collected in the northern region of Mozambique in Cabo Delgado, Montagues district from March to June 2017.

The oils obtained from Cymbopogon citratus and Ocimum basilicum were evaluated using the Kirby and Bauer method and the medium was Müller and Hinton supplemented with $2 \%$ glucose. A bacterial suspension was prepared in sterile physiological solution and fitted to 0.5 tube of the McFarland scale, which corresponds to approximately $1.5 \times 10^{6} \mathrm{CFU} / \mathrm{mL}$ of $S$. aureus strains ATCC 25923 and E. coli ATCC 25922, from owned by the Laboratory of Microbiology of the Faculty of Medicine, UEM.

$100 \mu \mathrm{L}$ aliquots of each bacterial suspension were surface seeded in Petri dishes containing about $15 \mathrm{~mL}$ of the MuellerHinton medium, with a thickness of approximately $4 \mathrm{~mm}$ (KirbyBauer, 1966).
Sixmillimetre diameter, sterilized filter paper disks containing volumes of $1,3,5$ and $10 \mu \mathrm{l}$ of pure oil without any dilution of each evaluated species were placed on the bacterial suspensions in the petri dishes. The control test was performed with antibiotic disks Ciprofloxacin containing $50 \mu \mathrm{g}$ per disc, commercially available.

Incubation was carried out in an oven at $36^{\circ} \mathrm{C}$ for 24 to 48 hours. The tests were performed in triplicate and the results expressed in $\mathrm{mm}$ by the arithmetic mean of the diameter of the inhibition halos formed around the discs in the 3 replicates. The diameters of the inhibition halos were interpreted according to the interpretation criteria recommended by NCCLS (National Committee for Clinical Laboratory Standards, 2000). Minimal Inhibitory Concentration (MIC) was determined by the disc diffusion method [4].

For the identification of the major compounds was performed using gas chromatography and gas chromatography coupled by mass spectrometry and this activity was performed at the Faculty of Sciences of the University of Lisbon.

\section{Results and Discussion}

Yields of extracted essentials oils

\begin{tabular}{|l|c|c|c|c|c|}
\hline $\begin{array}{l}\text { Name of } \\
\text { Plant }\end{array}$ & $\begin{array}{c}\text { Dried } \\
\text { leaves } \\
\text { mass (g) }\end{array}$ & $\begin{array}{c}\text { Essentials } \\
\text { (g) }\end{array}$ & oil & mass & $\begin{array}{c}\text { Yield } \\
\text { (\%) }\end{array}$ \\
\hline $\begin{array}{l}\text { Cymbopogom } \\
\text { citratus }\end{array}$ & $390,7 \mathrm{~g}$ & $3,0213 \mathrm{~g}$ & & & $0,77 \%$ \\
\hline $\begin{array}{l}\text { Ocimum } \\
\text { basilicum }\end{array}$ & $131,5 \mathrm{~g}$ & $3,0033 \mathrm{~g}$ & & & $2,28 \%$ \\
\hline
\end{tabular}

Table 1: Essential oil yield of Cymbopogom citratusand Ocimum basilicum.

There appears to be no large fluctuations in yield in response to data obtained by other authors regarding oils from this plant. The first step in the process of preparing and obtaining the essential oil using the dried leaves is the drying of the plant material, which has the purpose of removing the water and, thus, preventing hydrolysis and microbial growth reactions [5]. Looking at the income table above we can say that Ocimum basilicum had higher yield when compared to Cymbopogon citratus, by this way also it can be said that the leaves of this plant possess much essential oil. According to De Brito [6], studying essential oils of Cymbopogon citratus, an 
essential oil yield calculated on a fresh basis of $0.4669 \%$ was obtained. Authors, such as Matasyoh., et al [7]. The average oil content in the green leaves of the plant is $0.8 \%$ to $1.0 \%$, if considered in the conditions of this study, the yield obtained has a reasonable percentage if compared to those presented in the literature. It was observed that in the above culture system and under the conditions of this experiment there was good yield.

As for the dried leaves of the Ocimum basilicum species, this study showed a yield of $2.28 \%$ and when compared with studies with basil genotypes that indicated the essential oil content of dry mass of leaves and inflorescences ranged from 1, 36 to $1.70 \%$ and 4.01 to $5.17 \%$, respectively, according to [8]. And Blank., et al. [9] found mean values of $4.36 \%$ for these populations, demonstrating their superiority in relation to this study. To this it is indicated that this yield obtained in this research is acceptable and encouraging compared to many studies under the same conditions under which it was submitted as is the case of Genovese commercial cultivars yielding about $1.22 \%$ [9].

According to Burt [10], these yield variations of the essential oils for the same plant species can be attributed to differences in harvest time, soil type, regional climate, drying time and relative humidity of the day of the harvest.

Collection time is one of the factors that most influence the pharmacological activity of plant drugs, since the nature of the active constituents is not constant during the year. Currently, seasonal variations in the content of almost all classes of secondary metabolites are reported, with emphasis on essential oils (Giacomelli., et al. 2014).

For the development of this study the extraction was done with water by the hydrodistillation process, using the Clevenger apparatus, at the boiling temperature of water, since many substances are unstable at high temperatures. This process was used because a good yield of the oils was observed since it allows the steam extraction until the exhaustion of the oils in the leaves, and hydrodistillation is designated as the operation in which the extraction of the vegetal raw material is in a closed vessel, to a boiling temperature of water for an extended period (hours) under heating.

Identification and quantification of essential oil constituents of $C$. citratus and Ocimum basilicum Essentials oils of the species of this research were found, mostly terpenic compounds, such as monoterpenes, oxygenated monoterpenes, diterpenes and sesquiterpenes. According to Simões and Spitzer [11] "monoterpenes and sesquiterpenes are the most frequent terpenes in volatile oils". The major constituents identified in the two (2) essential oils of the dry leaves of plants showed a significant difference in relation to the quantification of the essential oils for the species. Among the several constituents identified, monoterpenes and/or oxygenated sesquiterpenes were predominant in all oils. In studies of the chemical composition of essential oils, a major active compound is generally identified, however, because they are composed of complex mixtures of volatile substances, the oils include in their composition other chemical components, such as a series of terpene hydrocarbons, esters, organic, aldehydes, ketones, phenols among others, in different concentrations [10].

The GC/MS analysis of dry leaves essential oils allowed the percentage identification of the major components of the essential oils in this chromatographic analysis of Ocimum basilicum to be $99.9 \%$ and Cymbopogon citratus $92.5 \%$ the yield data described above showed that Ocimum basilicum contains more oil.

The main compounds of the oils extracted from dry leaves were the monoterpene hydrocarbons, oxygenated monoterpenes, sesquiterpenes and oxygenated sesquiterpenes and diterpene hydrocarbons whose contents ranged from $0.7 \%$ to $77.9 \%$. The data found are in accordance with those described in the literature, where it is known that the essential oils of Cymbopogon citratus (chabakate) present the geranial isomer as the major compound and that gives activity. In general, of the essential oils analysed Methyl chavicol was the compound found in larger amounts in a sample (up to $77.9 \%$ ) of Ocimum basilicum. The majority of species were found in the majority of the essential oil of Cymbopogon citratus, with 14 components being the geranial (44.1\%) the majority, and in Ocimum basilicum, 30 components, with Methyl chavicol (77.9\%) being the major and found in much smaller amounts in the volatiles of the other essential oils, respectively. According to a study by Aquino., et al. [12] in Ocimum basilicum (basil) oil, 13 components were identified, $71.88 \%$ of linalool and $13.66 \%$ of geraniol, differing from this study. This discrepancy between the results compared probably is due to the difference in the climatic conditions of cultivation. 
The species Ocimum basilicum is very variable in its morphology, chromosome number and chemical composition of the essential oil, depending on the variations and chemotypes, the color and aroma of the leaves and inflorescences and the place where they were collected. These variations are attributed to the large number of crosses for the selection of characteristics such as smell and taste, allowing the description of many chemotypes of oils. During a chemotaxonomic survey of the genus Ocimum, it was found that even essential oils of the $O$. basilicum varieties do not have a homogeneous chemical composition. For example, Ocimum basilicum var. basilicum and 0 . basilicum var. purpurascens, which present five and three different chemotypes, respectively [13].

The peak of the chromatographic profile of the major compounds (peak areas) characterized in dry leaves of Cymbopogon citratus and Ocimum basilicum is shown in figure 1 respectively.

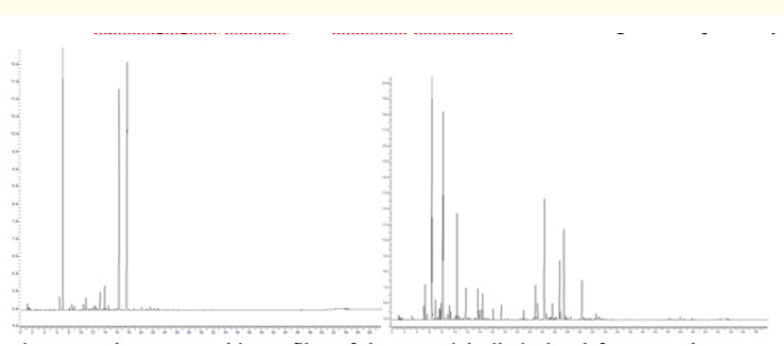

Figure 1: Chromatographic profiles of the essential oils isolated from Cymbopogom citratusand Ocimum basilicum.

Determination of the antibacterial activity of the essential oil of Cymbopogon citratus and Ocimum basilicum by the disc diffusion method Determination of Antimicrobial Activity by Disk Diffusion Method Through the diffusion technique [14] it can be observed according to figure 2, the formation of zones of inhibition halos of different sizes. According to Black [15] the antimicrobial activity in the disc diffusion technique occurs through the diffusion of the chemotherapeutic agent in all the directions of the agar, during the incubation.

Although it was characterized as a qualitative technique, the halos formed around the discs impregnated with the samples were compared to those obtained by the CIM, as was also done by Gonsalves [16].

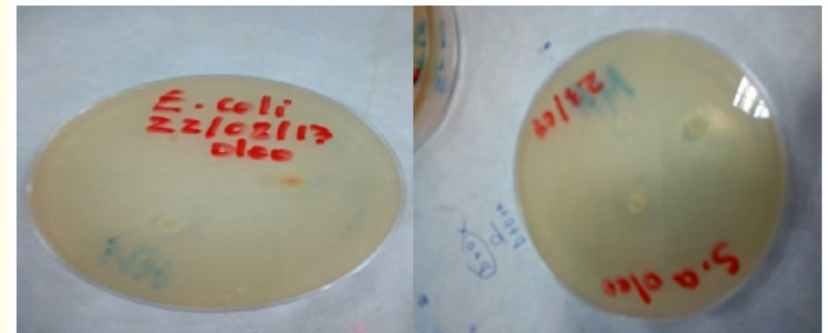

Figure 2: Formation of inhibition halos by the microorganisms used after incubation.

Grampositive and gramnegative bacteria were used for this test. According to Rios and Recio [17], the disc diffusion method is especially good for determining the relative potential of extracts or essential oils and to establish their antimicrobial spectrum, since it facilitates the use of different strains against the extract. According to Simões., et al. [18], this variation usually occurs as a function of the stage of the plant, as in full bloom or in the period before flowering. From this, it can be inferred from the table that two essential oils investigated, all had antibacterial activity and significantly inhibited the test microorganisms, being that in these microorganisms the essential oils created larger halos in the bacteria.

\begin{tabular}{|l|c|c|c|}
\hline Species & $\begin{array}{c}\text { Part of } \\
\text { The Plant }\end{array}$ & $\begin{array}{c}\text { E. coli ATCC } \\
\mathbf{2 5 9 2 2}\end{array}$ & $\begin{array}{c}\text { S. sureus ATCC } \\
\mathbf{2 5 9 2 3}\end{array}$ \\
\hline C. Citratus & Leaf & + & + \\
\hline O. Basilicum & Leaf & + & + \\
\hline Controlbacteria & 1 & $24 \mathrm{mn}$ & $23 \mathrm{~mm}$ \\
\hline
\end{tabular}

Table 2: Evaluation of the inferred from the crude essential oils of the species studied by the disc diffusion technique.

-: absence of halo; +: Presence of inhibition halo; The values of the inhibition halos exclude the disc diameter $(6 \mathrm{~mm})$. 1. Ciprofloxacin.

Regarding bacteria, the gram positive was the most sensitive to the essential oils in this study when compared to the gram negative that in some concentrations had an inhibition or smaller halos.

According to Fennell., et al. [19] the variations regarding the determination of the MIC of the essential oils of plants can be attributed to several factors. These include the methodology applied, the 
microorganism evaluated, the origin of the plant, the time of collection, whether the essential oils were prepared from dried plants and the amount of extract tested.

According to some authors like Black [15] the difference of activity against Grampositive and Gramnegative bacteria seems to derive from the constitution of the bacterial cell wall, composed of peptidoglycan, complex polymer, besides this structure, Gramnegative bacteria present a membrane which gives this group of microorganisms an effective permeability barrier, restricting the penetration of some compounds. The knowledge of the differences between the walls of Grampositive and Gramnegative bacteria is of the highest relevance for the study of the mechanism of action of chemotherapeutics, pathogenicity and so many subjects directly related to the chemical composition and structure of the bacterial wall [20]. All bacterial species tested were susceptible to the action of oils with significant differences.

Gramnegative bacteria, E. coli, were the most sensitive to the essential oils tested when compared to grampositive bacteria, because their microbial growth was inhibited for most of the oils. As for Grampositive bacteria, S. aureus was not very sensitive to all the oils tested and also can not refer to resistance because there were halos, but not many halos. The reason for the difference in sensitivity between Grampositive and Gramnegative bacteria may be related to differences in the morphological constitution of these microorganisms. Gramnegative bacteria are reported to have resistance to many of the marketed antibiotics and E. coli is the most prominent [21]. The complexity of Gramnegative makes them less susceptible to antimicrobial agents. These results indicate a certain specificity of action of these essential oils, which is interesting for an antimicrobial drug, since it gives certain selectivity.

The values of the antimicrobial activity by the disc diffusion method obtained with the essential oils in this study are comparable to those reported for other essential oils of plants [21], indicating that the essential oils of these species can be seen as potential agents antimicrobial agents for the control of important bacterial and fungal species.

However, there are often large differences in the antibacterial activity reported on the oil from the same plant. The reasons for this variability may be due to geographic sources, harvesting times, genotype, climate and extraction method, factors that influence the chemical composition and relative proportions of each constituent in the essential oil of the plant [10]. In the present study, these trends were observed both in relation to the concentration factor, whose inhibitory effects were positively associated with the concentration of the oil, as in relation to the species. These points were detected when analysing the halos formed by these crude essential oils both on micro orphisms (Figure 3).

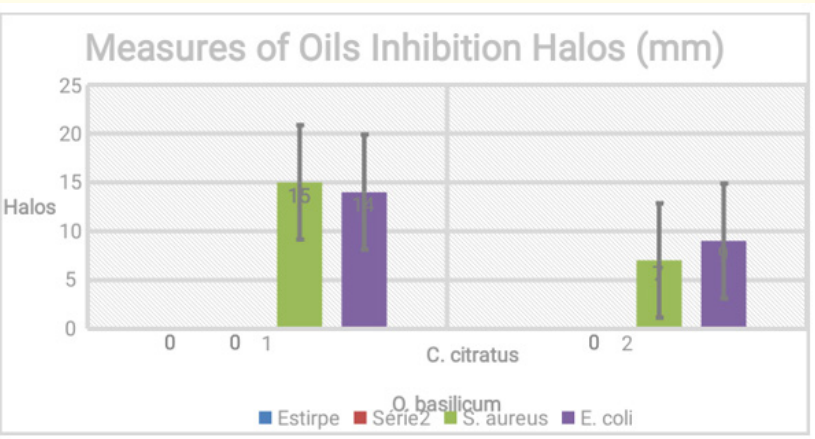

Figure 3: Mean values of inhibition halos of the crude essential oils against $E$. coli and $S$. aureus.

The results observed in this study are in agreement with those obtained by Bauer where inhibition halo formations were observed in the essential oil samples against the E. coli, S. aureus microorganisms. And of the essential oils of Cymbopogon Citratus and Ocimum basilicum according to the graph has larger halos of inhibition with all microorganisms tests the Cymbopogon citratus has larger halos and can be considered with effective antibacterial.

Determination of antibacterial activity and minimal inhibitory concentration (MIC) The antibacterial activity of plant extracts is evaluated by determining a small amount of the substance necessary to inhibit the growth of the test microorganism; this value is known as Minimum Inhibitory Concentration (MIC) [23].

The Minimum Inhibitory Concentration (MIC) assay is obtained by macro or microdilution of compounds consisting of preparing successive dilutions of the antimicrobial to be tested in solid culture media or liquid, to sow the microorganism and after incubation verify the lowest concentration (greater dilution) of the antimicrobial that inhibited the growth of the microorganism [24]. The advantages of this method are to provide more quantitative 
Essential Oils from Two Species of Aromatics Plants from Mozambique, their Chemical Constituents and Bioactivity on Escherichia coli and Staphylococcus aureus

information and to be able to be applied to a wider variety of isolates than the diffusion tests [25]. And the dilutions in this study were made using 99\% DMSO to measure the minimum inhibitory concentration (MIC).

\begin{tabular}{|l|c|c|c|c|}
\hline \multirow{2}{*}{ Strain } & Specie & \multicolumn{3}{|c|}{$\begin{array}{c}\text { Concentration of essential } \\
\text { oil (mg/ ml) }\end{array}$} \\
\hline & & 50 & 100 & 200 \\
\hline E. coli & C. Citratus & $6.7(1.65 \%)$ & 7 & 11.3 \\
\hline & O. Basilicum & $7.7(1.38 \%)$ & 7.7 & 7.7 \\
\hline S. aureus & C. Citratus & $6.3(1.38 \%)$ & 6.7 & 8.2 \\
\hline & O. Basilicum & $6(1.38 \%)$ & 6.3 & 6 \\
\hline
\end{tabular}

Table 3: Results of the mean minimum inhibitory concentrations (mg. mL1) of the essential oils against strains E. coil S. aureus.

By the technique, the essential oils inhibited in the same concentration that was $50 \mathrm{mg} / \mathrm{ml}$, but differing in the sizes of the halos formed, where they were verified smaller halos of the MICs were registered for the Gram positive bacteria ( $S$. aureus), confirming the higher efficiency of the oils for this group. The essential oils of Cymbopogon citratus were more effective demonstrating agreement with the studies of Machado., et al. [26] evaluating the antimicrobial activity verified that the minimum inhibitory concentration of C. citratus for the bacteria $E$. coli and $S$. aureus obtained mean values between 0.34 and $5.5 \mathrm{mg} / \mathrm{ml}$, significantly disagreeing with this study that had the minimum inhibitory concentration of 50 $\mathrm{mg} / \mathrm{ml}$. The species Cymbopogon citratus shows marked antifungal activity against the $C$. albicans strain, surpassing the values of inhibition of the standard drug (nystatin). It is suggested that the antifungal effect of the essential oil C. citratus is due to the majority presence of geranial, which is an oxygenated terpenoid. And with this technique of CIM determination, the 2 essential oils confirmed the activity observed by the disc diffusion technique and, in addition, inhibited, in varied extensions, the growth of microorganisms. This variation can be justified by the presence of different substances in the samples, because more polar molecules or molecules with higher molecular mass may be more soluble and easier to disperse in liquid medium [27]. In order to evaluate the antimicrobial action of Ocimum basilicum essential oil, it has been shown that it is active on bacterial strains up to $2 \%$ concentration, differing of our study, in which it was active on strains up to $1.66 \%$, however, in both cases, the antibacterial and antifungal activity of the product was verified. Different methods used to test antibacterial activity have shown that essential oils obtained from aerial parts of Ocimum basilicum have a strong inhibitory effect on Staphylococcus, Enterococcus and Pseudomonas [28].

The antimicrobial activity of $O$. basilicum essential oil against microorganisms has been widely reported. Prasad., et al. (1986) and Farag., et al. (1989) also point out that the essential oil obtained from 0 . basilicum and other Ocimum species are more efficient against Gram positive bacteria (Bacilus sp., Staphylococcus sp., Micrococcus sp., Lactobacillus sp.) Than against Gram-negative bacteria (Enterobacter sp., Pseudomonas sp., Salmonella sp.) [2932].

\section{Final Considerations}

In the experimental conditions used in this article we can conclude that the study of the essentials oils of dry leaves of Cymbopogon citratus and Ocimum basilicum allowed the identification of good yields with respect to the method used for extraction and this result may be associated to the stage of life, the period, place and until the time of the harvest of the plants. The essential oils tested showed activity against the two (2) test microorganisms, using the Minimal Inhibitory Concentration method per disc of $50 \mathrm{mg} / \mathrm{ml}$, and its percentage ranged from $1.38 \%$ to $1.65 \%$ demonstrating greater sensitivity of this technique; and the results obtained by MIC (most sensitive organisms) are significant with the findings of the disc diffusion methodology. The oils showed the presence of terpenes, monoterpene, diterpene hydrocarbons, oxygenated monoterpenes and sesquiterpenes with antibacterial activity.

\section{Bibliography}

1. Ribeiro A., et al. "Ethnobotanical survey in Canhane village, district of Massingir, Mozambique: medicinal plants and traditional knowledge". Journal of Ethnobiology and Ethnomedicine (2010): 633.

2. Krog M., et al. "Medicinal plant markets and trade in Maputo Mozambique". Forest and Landscape Working Papers 16, Danish Center for Forest Landscaping and Planning, KVL (2006).

3. MBB. Report on a study into the potential of aromatic plants for essential oils in ozambique, Cape Town, South Africa (2006).

4. NCCLS. 940 west valley road, suíte 1400; Wayne, Pennsylvania 190871898, USA (2003). 
5. Bacchi EM. “Controlled equalidadedefitoterápicos”. In: Distasi, L.C. (org). plantasmedicinais: arteeciência. São Paulo: Universidade estadual Paulista (1996): 169197.

6. De Brito and Ana Maria Guedes. Avaliaçãoda atividadeantileishmanialdosóleos essenciaisdas plantas Cymbopogoncitratus (DC.) Stapf., Eucalyptuscitriodora Hook., Mentha arvensis L., e Menthapiperita L. Universidade Tiradentes. Dissertação de mestrado em Saúde (2017).

7. Matasyoh JC., et al. "Chemical composition of Cymbopogon citrates essential oil and its effect on my cotoxigenic Aspergillus species". African Journal of Food Science 5 (2011): 138142.

8. Luz JMQ., et al. "Content, yield and chemical composition of essential oils of basil under the pressure of the bed". Brazilian Horticulture 27 (2009): 349353.

9. Blank A.F., et al. "Comportament of enotípicoegenotípicodepopulaçõesde manjericão". Horticultura Brasileira 28.3 (2010): 305310.

10. Burt S. "Essential oils: their antibacterial properties and potential applications in foods-a review". International Journal of Food Microbiology 94 (2004): 223253.

11. Simões CMO., et al. Farmacognosia. Editora da Universidade Federal de Santa Catarina, 2ª edição. (2000): 387416.

12. Aquino., et al. "Atividade Antimicrobiana Dos Óleos Essenciais De ErvaCidreira E Manjericão FrenteA Bactérias DeCarnes Bovinas". Alimentos e Nutrição Araraquara 21.4 (2010): 523524.

13. Grayer RJ., et al. "Infra specific taxonomy and essential oil chemotypes in Sweet basil, ocimumbasilicum". Phytochemistry 43.5 (1996): 10331039.

14. Bauer AW., et al. "Antibiotic susceptibity testing by a standardized single disk method". American Journal of Clinical Pathology 4 (1966): 493496.

15. Black JG. "Microbiologia: fundamentose perspectives". 4edition. Rio de Janeiro: Guanabara Koogan (2002): 829.

16. Gonsalves JM. "Avaliaçãoda actividade antimicrobian aetriagemfitoquímica dosextractosdee species da família asteraceaeencontradasnosemiáridobaiano". Dissertação de Mestrado. Feira de Santa, Bahia (2010).

17. Ríos JL and Recio MC. "Medicinal plant sand anti microbial activity". Journal of Ethnopharmacology 100 (2005): 8084.
18. Simões CMO., et al. Farmacognosia: daplantaaomedicamento. 6 a ed. Porto alegre: editora da UGRGS; Florianopolis: editora da UFSC (2007).

19. Fennell CW., et al. "Assessing African medicinal plants for efficacy and safety: agricultural and storage practices". Journal of Ethnopharmacology 95 (2004): 113121.

20. Schaechter M., et al. "Microbiologia". 33 Ed. Guanabara Koogan: (2002): 120127.

21. Menezes EA., et al. "Frequency and percentage of susceptibility of isolated bacteria in patients in the intensive care unit of Fortaleza". The Jornal Brasileiro de Patologia e Medicina Laboratorial 43 (2007): 149155.

22. Sandri IG., et al. "Antimicrobial activity of the essential oils of Brazilian species of the genus Cunila against food borne pathogens and spoiling bacteria". Food Chemistry 103 (2007): 823828.

23. Ostrosky EA., et al. "Methods for the evaluation of antimicrobial activity and determination of the minimum inhibitory concentration (MIC) of medicinal plants". Pharmacognosy (2008).

24. CLSI. Performance Standards for Antimicrobial Disk Susceptibility Tests; Approved Standard-Eighth Edition. CLSI document M2A8 (ISBN 1562384856) (2003).

25. Koneman EW., et al. "Diagnósticomicrobiológico". 5 ed. Rio de Janeiro: Medsi (2011): 494.

26. Machado Terezinha Feitosa., et al. "Actividade anti microbianadoóleo essencial decapimlimão. Embrapa Agroindústria Tropical, ISSN16796543,1ํㅡ edição, Fortaleza (2012).

27. Valgas C., et al. "Screening methods to determine antibacterial activity of natural". Brazilian journal of Microbiology 38 (2007).

28. Opalchenova G and Obreshkova D. "Comparative studies on the activity of basil- an essential oil from Ocimum basilicumagainst multi drug resistant clinical isolates of the genera Staphylococcus, Enterococcus and Pseudomonas by different test". Journal of Microbiology Methods 54 (2003): 105110.

29. Silva F., et al. "Basil conservation affected by cropping season, harvesttime and storage period". Pesquisa Agropecuária Brasileira, Brasília 40 (2005): 323328. 
30. Costa CMGR., et al. "Efeitoinibitóriodoóleoessencialdemanjericãosobreo crescimento invitrode Erwiniacarotovora". Tecnologia and Ciência Agropecuária 3 (2009): 3538.

31. Hakkim FL., et al. "Antioxidant property of selected Ocimum species and their secondary metabolite content". Journal of Medicinal Plants Research 2.9 (2008): 250257.

32. Pinto DAI., et al. "Productivity of oil quality and essential limestone, Cymbopogoncitratus, DC., Subjected to different irrigation slides". Revista Brasileira de Farmacognosia 16 (2014).

\section{Volume 3 Issue 10 October 2019}

(C) All rights are reserved by Alfredo Bartolomeu., et al. 